\title{
PLATÃO E NIETZSCHE, UM CONFLITO ENTRE ACRASIA E VONTADE DE PODER
}

\author{
Plato and Nietzsche, a Conflict between Acrasia and Will to Power.
}

Francisco de Assis Silva Neto ${ }^{1}$

\begin{abstract}
RESUMO: A presente proposta de investigação, versará acerca de uma possível relação entre o conceito platônico de acrasia e o conceito nietzschiano de vontade de poder. O que propomos especular é que a constituição de ambos os termos possuem uma raiz em comum, no que tange a conduta dos indivíduos, diferindo apenas no posicionamento filosófico acerca da compreensão de tal postura, ou seja, uma questão de perspectiva. A pesquisa será dividia em momentos distintos que tem por intuito validar a conjectura proposta. No primeiro momento, expor de modo panorâmico a compreensão de Platão acerca do problema da acrasia como uma anomalia que levaria a uma conduta de excessos e, por tanto, danosa para os cidadãos e para a sociedade. Em um segundo momento, expor a compreensão de Nietzsche acerca da vontade de poder enquanto constituinte próprio e de valoração da vida, buscando demonstrar uma possível ligação entre os dois termos, correlacionando-os a conduta humana e propondo uma profunda influência do pensamento de Platão em Friedrich Nietzsche (1844-1900).
\end{abstract}

PALAVRAS-CHAVE: Acrasia. Vontade de poder. Relação.

ABSTRACT: This research proposal deals with a possible relationship between the Platonic concept of acrasia and the nietzschean concept of will to power. What is specific to the constitution of both terms, has a common root, does not have a conduct of different use, only a philosophical position on the implementation of such an approach, that is, a matter of perspective. A research will be divided into different moments, in order to validate a conjecture proposal. In the first instance, export Plato's panoramic mode and understanding of the problem of acrasia as an anomaly that would lead to an excess and therefore harmful conduct for individuals and society. In a second moment, expose Nietzsche's understanding of the will to power, as constituted by himself and with life value, seeking to show a possible choice between the two terms, correlating them with a human conduct and proposing a similarity between the two. thoughts of Plato and Friedrich Nietzsche (1844-1900).

KEYWORDS: Acrasia. Will to power. Relationship.

\section{Introdução}

A relação que propomos demonstrar, versará sobre a possível relação conceitual entre a constituição da acrasia para a filosofia de Platão e a proposta nietzschiana de uma vontade de poder. ${ }^{2}$ A pertinência dessa especulação se dá, em partes, pela recorrência do filósofo grego nas produções

\footnotetext{
${ }^{1}$ Graduado em Filosofia pela Universidade Estadual do Piauí (UESPI). Mestrando em Filosofia pela Universidade Federal do Piauí (UFPI). E-mail: chiconeto1910@hotmail.com. Lattes: http://lattes.cnpq.br/4527394151370502

${ }^{2}$ Optamos por essa tradução em detrimento de outras possíveis, visando estar em consonância com as traduções das obras de Nietzsche que serão utilizadas para compor a bibliografia dessa pesquisa.
} 
do filósofo alemão. E de como o movimento de crítica nietzschiana a filosofia socrático-platônica tem sido um tema multifacetado na história da filosofia, todavia, não esgotado.

Entretanto, a vertente que propomos para essa pesquisa, não será a que perpassou por grande parte da história da filosofia, por considerarmos suficientemente trabalhada. Iremos utilizar a figura de Platão para além dos dualismos, no que tangerá a abordagem da acrasia, a saber, a possível tríade que reside no pensamento platônico e que é esboçada na República e desenvolvida por muitos de seus comentadores ${ }^{3}$ contemporâneos.

Essa abordagem que defende um dualismo rígido em Platão e uma subordinação do corpo em relação à alma foi uma das mais aceitas e difundidas ao longo da tradição que estudou e bebeu da fonte filosófica platônica. Entretanto, ao longo de toda sua produção escrita, o filósofo não expressou somente uma tendência dualista, existindo teorias que apontam, inclusive, o dualismo como uma incompreensão da proposta de Platão, essas reinterpretações e reflexões ganharam espaço para serem pensadas e serão as que propomos utilizar.

É consenso, sobre a filosofia de Nietzsche, que ele foi um autor das críticas e inversões, por exemplo, não é difícil apontar a influência que o jovem filósofo recebeu de perspectivas como a de Arthur Schopenhauer (1788-1860) ou mesmo a de Richard Wagner (1813-1883) no começo de sua produção filosófica. Estas mesmas influências viriam a se converter em rompimentos e, porque não em desprezo, em um Nietzsche mais maduro. Logo, parece válido pensar que do mesmo modo poderia ter ocorrido com Platão, não implicando em uma incoerência especular tal conjectura.

Ademais, cabe apontar que apesar das críticas, o autor demonstrou um profundo interesse pelo filósofo, uma vez que se debruçou sobre suas perspectivas para buscar criticá-las, e muitas vezes partilhar delas. Pode-se retirar de tal interesse, uma possível admiração invertida, logo, não seria coerente uma crítica tão brusca e rebuscada acerca de uma premissa simplista ou de pouca relevância. É certo que Nietzsche conhecia profundamente a obra do pensador grego e sabia da importância de suas contribuições para a história da filosofia.

Afim de delimitar nossa perspectiva, uma vez que existem uma variedade de interseções e influências entre a perceptiva platônica e a nietzschiana, escolhemos como ponto fulcral uma possível relação entre a noção de acrasia e vontade de poder, o que implicará em toda a estrutura da pesquisa tender para essa relação, se utilizando de obras de ambos os filósofos e em certas circunstâncias remetendo-se a comentadores para coadunar com a interpretação proposta.

É comumente aceito por estudiosos da filosofia de Nietzsche, que a noção de vontade teria sido oriunda do pensamento schopenhauriano e reformulada pela filosofia nietzschiana. O que

\footnotetext{
${ }^{3}$ Christopher Bobonich (2002), Ferrari (2007), Maria Dulce Reis (2017), entre outros.
} 
propomos especular, não destoa dessa relação, entretanto, buscamos investigar e argumentar que essa noção já existe no pensamento de Platão, apenas sob um filtro conceitual distinto. Dito isto, buscaremos conjecturar acerca da acrasia como possível influenciadora da perspectiva de vontade de poder. Não temos por intuito conceitual eleger um novo horizonte interpretativo, mas especular acerca de uma temática, o que se configura como uma das atividades por excelência da filosofia.

Para justificar nossa interpretação, buscaremos apontar passagens específicas em que a conduta do filósofo alemão em seus textos parece refletir e expandir a de opositores que foram aparentemente refutados por Sócrates, nos diálogos de Platão. Remetendo, em partes, ao projeto de maturidade nietzschiano, a saber, a transvaloração de todos os valores, que teria como um dos resultados, a inversão do platonismo.

Doravante, entender-se-á ambos como filósofos de constituições teóricas distintas, porém, a partir do que foi proposto, não inconciliáveis, logo, não teremos por intuito eleger qualquer hierarquia entre posturas e posicionamentos, sob pena de cair em divagações e precipitações teóricas. Teremos por intuito e fio condutor ao longo da produção, a explicitação clara das questões propostas, de modo a corroborar com a plausibilidade das conjecturas que dão margens para o desenvolvimento dessa pesquisa.

\section{Desenvolvimento}

\subsection{A vida na república, acrasía para Platão e vida e corpo para Nietzsche}

A possibilidade do homem acrático, configura-se como uma problemática que perpassa o processo de maturação do pensamento de Platão, em menor ou em maior grau. Despontando para o assunto desde a fase dita socrática, ainda na juventude do filósofo, em obras como Protágoras e Górgias, por mais que ainda não carregassem o termo acrasia. Logo, será somente na República que o pensador grego irá se debruçar com maior ênfase em tal conceito, suas possibilidades e sua relevância no corpo social.

Nos dispomos, nesse ponto, em buscar apresentar de modo panorâmico a concepção de acrasia para Platão, ao mesmo passo que buscaremos demonstrar como esse modelo interpretativo se aproxima da filosofia nietzschiana, destoando apenas em perspectiva, mas não ignorando por completo a raiz da compreensão, a saber, a conduta do homem que está imerso em ambos os conceitos. Acerca desse aspecto, propomos que: “(...) a discussão da acrasia se inicia propriamente dita na República com a divisão da alma em três partes. Cada uma delas possui seus desejos, suas particularidades (cognitiva, emotiva, apetitiva), (...)" (FEITOSA, 2017, p.217) Sob a afirmação anterior que propomos nos pautar. 
A abordagem dada por Platão a concepção de "desgoverno da alma", está amparada no ambiente social de sua pólis utópica, a concebendo como circunstância que levaria seus cidadãos a escolhas pouco racionais e mais emotivas, comprometendo a possibilidade de estrutura social coesa e coerente. Logo, cada cidadão, na obra platônica, possuiria uma função a qual deveria executar com a máxima excelência.

Entretanto, a tripartição da alma, que necessariamente levaria a um pluralismo psicológico dos cidadãos, era um fato alarmante para Platão, uma vez que incorreria em uma multiplicidade de vontades e escolhas, afetando o seio social, uma vez que: “(...) Todo o conflito gerado pela alma tem uma dimensão moral que refletirá no comportamento social do homem.” (FEITOSA, 2017, p.218). Este aspecto é o gatilho da reflexão que se segue. Segundo Platão

O difícil é saber se fazemos tudo por meio de um único princípio, ou se cada um deles tem uma função diferente, a saber: se aprendemos com um, colerizamos-nos com outro, e procuramos satisfazer nossos desejos por meio de um terceiro, o da alimentação, da procriação e outros da mesma natureza, ou se será com toda a alma que realizamos cada um desses atos, quando nos dispomos a isso? Eis que se me afigura difícil decidir por maneira satisfatória. (REP, 436-b)

Notemos que os exemplos utilizados pelo filósofo são necessidades básicas dos indivíduos e todas comumente relacionadas ao corpo, entretanto, Platão as coloca como necessidades da alma. E atribuindo uma desmedida a conduta dos indivíduos que pautassem suas ações visando uma saciedade das necessidades mais imediatas. Nesse exemplo, especificamente, necessidades mais simples, seriam aplacadas de forma mais simples. Entretanto, esse conflito de vontades se expande e existe em todas as camadas constituintes dos cidadãos.

Nesse ambiente de cisão da alma, evidencia-se o conflito entre contrários, a parte mais racional da alma é confrontada pela parte apetitiva, que estaria mais inclinada aos desejos do corpo, aos quais podemos citar os apetites sexuais e os vícios. Todavia: "Há ainda a parte intermediária (thymós) que atua principalmente para a razão, todas agindo na mesma alma com diferentes sujeitos." (FEITOSA, 2017, p.218). Nesse ponto em especial, fica evidente a primazia de Platão pela racionalidade, mesmo sofrendo menos influência do socratismo. Nesse sentido, Nietzsche nos propõem que "A “razão" é a causa de que falseamos o testemunho dos sentidos. Na medida em que indicam o devir, o fluxo, a transitoriedade, os sentidos não mentem. Com isso, porém, Heráclito $^{5}$ terá eternamente razão. (NIETZSCHE, 2016, p.26).

\footnotetext{
4 "O termo acrasia significa o desgoverno da alma, a falta de controle mediante os conflitos causados pelos desejos e paixões que conduzem o homem ao erro." (FEITOSA, 2017, p.217)

Heráclito (535 a.C. - 475 a.c) foi um filósofo pré-socrático que exerceu grande influência no pensamento nietzschiano, em especial, com seu conceito de vir-a-ser como um eterno devir em relação com o mundo e com a vida. A influência do devir proposto por Heráclito no pensamento nietzschiano é utilizado como contraponto à noção idealista concreta e imutável pensada por Sócrates e Platão, na qual noções eternas e modelos perfeitos são
} 
O que Nietzsche nos apresenta é o oposto da significação platônica, não à toa a alma possui duas partes voltadas a racionalidade, este seria um modo de evitamento dos sentidos provenientes do corpo e portanto uma alternativa para as necessidades menos controláveis, que deveriam ser regidas pela razão.

Todavia, no que diz respeito a divisão da alma, Platão admite que isso poderia incorrer em uma inconstância do próprio querer do homem, uma vez que estaria dividido por necessidades plurais e quase sempre opostas. Vale ressaltar que nesse ponto, a acrasia é tratada como uma possibilidade, a parte de uma série de conjecturas. Como examina Platão: "Por exemplo, não dirás sempre que a alma de quem deseja tende para o objeto desejado ou que atrai para si o que deseja possuir...” (REP, 437-b)

Como exposto anteriormente, Platão não se abstém de conjecturar que mesmo a alma com uma superioridade em partes mais racionais, poderia demonstrar fraqueza frente a vontade de realização de alguma inclinação. Porém, na possibilidade de diálogo entre as partes, existe a alternativa de superação dos apetites e contenção do sujeito para a escolha mais temperante e portanto melhor para o cidadão e a pólis, uma vez que todo esse conflito se dá, com esse homem enquanto uma extensão viva de sua politeia. Pressupondo uma espécie de controle dos seres frente as vontades. Nietzsche argumenta que

Quanto à superstição dos lógicos, nunca me cansarei de sublinhar um pequeno fato que esses supersticiosos não admitem de bom grado - a saber, que um pensamento vem quando 'ele' quer, e não quando 'eu' quero; de modo que é um falseamento da realidade efetiva dizer: o sujeito 'eu' é a condição do predicado 'penso'. (NIETZSCHE, 1998, p.23)

Longe de ser apenas uma crítica a noção cartesiana de cógito, o filósofo está apontando que não existe um controle racional de nossos pensamentos e vontades, assim como propõem Platão ao conceber a parte da mediania da alma, estando mais próxima da razão, justamente com o objetivo de praticar ou meramente de buscar esse controle. O que pode-se deduzir acerca dessa premissa seria um descontrole dos indivíduos, que recairia em escolhas arbitrárias e desconexas. $\mathrm{O}$ que não seria viável, uma vez que tanto Platão quanto Nietzsche, pensaram esse homem inserido em uma convivência social e o filósofo alemão não propunha sua concepção como modo de boicotar a própria noção de legalidade, mas apenas de moralidade.

Platão observa que a tríade da alma traria mais conflitos que soluções para a questão da acrasia, uma vez que três partes distintas se tornariam quase inconciliáveis e para o filósofo grego, ao contrário de Nietzsche, isso seria inadmissível se pensássemos que esse cidadão deveria refletir a perfeição política e organizacional da República platônica.

implantados. Por mais que a dialética socrática pareça versátil, aparentemente possui como fundo teleológico a produção de verdades imutáveis e essências eternas. 
Em certo sentido, Platão desenvolve um movimento de auto crítica na sua obra, o que reflete, em partes, a necessidade e dificuldade de rompimento com o socratismo. Mas, no decorrer da obra, o filósofo propõem outra possibilidade para se pensar o fenômeno da acrasia. Nesse ponto, admitindo: "Ao que parece, o que impera na pessoa é uma competição de desejos, cada um com sua força que determinará para onde essa força queira conduzir." (FEITOSA, 2017, p.222). Com esse contexto específico que surge a interseção que buscamos propor, entre o conceito de acrasia em relação com a vontade de poder. Platão, ao admitir tal abertura, abre um leque de possibilidades interpretativas, como a que estamos a propor.

Entretanto, o pensador grego se ampara na educação das classes sociais componentes da República para evitar que o desgoverno da alma se configure como uma patologia social, uma vez que admitiu que as inclinações e desejos eram componentes dos cidadãos e não se poderia livrarse deles, e para que assim não acarretassem problemas estruturais e de convivência no seu modelo ideal de cidade. Logo: "A educação possibilita uma visão de classe ou de mundo pela via da moralidade.” (FEITOSA, 2017, p.223)

\subsection{Nietzsche e Platão, acrasia ou vontade?}

Como propomos especular anteriormente, a partir do que foi posto como constituição da acrasia, propomos ampliar o ponto de interseção em que acreditamos que a mesma se relaciona com a noção de vontade de poder , visando demonstrar que ambas possuem mais proximidades que antípodas conceituais. Partiremos, em princípio, tentando demonstrar o que Nietzsche entende como a força motriz da realidade a qual estamos inseridos e em especial como relaciona-se com o sujeito, refletindo na sua conduta e necessidades, desde as mais imediatas até as de longo prazo.

Doravante, sempre que nos remetermos a um dos conceitos, seja o platônico ou o nietzschiano, estaremos propondo uma relação entre seus constituintes, logo deve-se buscar pensalos em comunhão e em relação necessária com a conduta do homens em sociedade.

A proposta da filosofia nietzschiana, assim como a de Platão, pode ser pensada em forma de tríade, nesse sentido, entre corpo, mundo e vida. Nesse contexto, o trabalho visa argumentar

\footnotetext{
${ }^{6} \mathrm{O}$ conceito de vontade surge na filosofia nietzschiana a partir da influência do pensamento de Schopenhauer, nas perspectivas do jovem Nietzsche, assim como foi apontado anteriormente. Ao longo de sua produção e amadurecimento filosófico, o autor passa por mudanças conceituais e acaba abandonando a concepção schopenhauriana e desenvolve o seu conceito próprio, denominado como vontade de poder. A vontade para Nietzsche está ligada a noção de liberdade, fundamento da existência. No entanto, a proposta socrático-platônica de correspondência entre razão, virtude e felicidade, tolhe a potência geradora da vida, criativa e libertária por excelência. Assim a racionalização da vida, sugerida por Sócrates, poderia culminar em uma castração da liberdade dos indivíduos, uma vez que aquilo que soa como uma escolha, a felicidade, aparece como uma destinação. Em contraponto a isso, a vontade de poder surge no âmago da filosofia nietzschiana como conceito de extrema relevância para a compreensão do pensamento do autor.
} 
como essas três extensões da realidade devem ser postas para romper com posturas idealistas que castram as liberdades individuais e enfraquecem o próprio ato de viver. Nietzsche propõe, nos moldes de sua vontade de poder, uma nova forma de concepção do corpo, um corpo que é vida, um corpo que é vital para se existir enquanto sujeito no mundo das possibilidades.

Propomos certa ênfase na compreensão de Nietzsche acerca das vontades do corpo, para evidenciar o contraponto em relação as vontades plurais, oriundas da tripartição da alma. Enquanto o que vem da parte apetitiva, segundo Platão, deveria ser controlada pela razão, pois necessariamente estaria acompanhada de dano moral, ou descontrole, o que é proveniente do corpo, para Nietzsche, deve ser aceito, compreendido e até certo ponto, estimulado.

Nesse sentido, Nietzsche supôs se opor por completo a Platão, formulando antípodas conceituais para pontos específicos, tornando ainda mais evidente a sua relação com o platonismo. Buscando sempre contrariar o modo de filosofar platônico, que seria para o grego: "Por ser essa essência do homem, não admitia que a alma, em sua pureza e nostalgia do mundo perfeito, pudesse misturar-se à dimensão impura e perecível da matéria corpórea, representada pelo corpo.” (FEITOSA, 2017, p.216). Por outra perspectiva o autor alemão, nas palavras de Barrenechea

Ele propõe o corpo como fio condutor interpretativo, como uma perspectiva ainda "mais fascinante e misteriosa" do que a crença na alma ou no espírito. O corpo apresenta-se, na interpretação nietzschiana, como o mais efetivo e o mais seguro para abordar todas as questões relevantes da vida humana. Trata-se de um "milagre dos milagres", no qual a consciência e todas as atividades espirituais não são mais do que instrumentos dessa "prodigiosa síntese de seres viventes" que é a totalidade orgânica." (BARRENECHEA, 2017, p.47)

Citamos o corpo para elucidar a antípoda conceitual que é elabora por Nietzsche, um contraponto fundamental a proposta platônica, que se ampara e se fundamenta na instância metafísica da alma, que como explicitado anteriormente seria a fonte principal da acrasia. Entretanto, a vontade de poder para o filósofo alemão, residiria na vida como um todo, mas encontraria no corpo a sua instância máxima. Nas palavras de Zaratustra: "Corpo sou eu e alma- assim fala a criança. E por que não se deveria falar como as crianças? Mas o desperto, o sabedor, diz: corpo sou eu inteiramente, e nada mais; e alma é apenas uma palavra para um algo no corpo." (NIETZSCHE, 2011, p.35)

Pode-se deduzir que se existe de fato uma alma, ela estaria necessariamente contida no corpo, nesse sentido Zaratustra corrobora Platão, ${ }^{7}$ todavia, não existia em hipótese alguma uma

\footnotetext{
${ }^{7}$ Segundo Thomas M. Robinson: "Mostra-se claro que o corpo é também uma fonte potencial de dano moral, quando afirma que este, com sua presença, 'contamina' a alma, 'preenche-a com suas luxúrias' e 'enfeitiça-a com suas paixões e prazeres'.” (ROBINSON,1998, p.340).
}

Cadernos Cajuína, V. 6, N. 1, 2021, p. 48-59. 
primazia do primeiro em relação ao segundo, pelo contrário, "o corpo é uma grande razão" (NIETZSCHE, 2011, p.36).

Como proposto anteriormente, podemos observar mais claramente o movimento de cisão que é elaborado por Nietzsche em relação a Platão, todavia ainda não é o ponto fundamental a ser colocado. Para buscar demonstrar uma noção de proto-vontade-de-poder ${ }^{8}$, remeteremos a fala de Cálicles para Sócrates no diálogo platônico Górgias

Foi isso, precisamente, Sócrates. Pois como poderá ser feliz quem for escravo do que quer que seja? O belo e justo por natureza, digo-o sem o menor constrangimento, é que quem quiser viver de verdade, longe de reprimir os apetites, terá que permitir que se expandam o quanto possível, e quando se encontrarem no auge, ser capaz de alimentá-los com denodo e inteligência e de satisfazer a todos eles à medida que se forem manifestando. (492 a)

A fala anterior, está fundamentando uma autonomia da vontade dos seres, pressupondo que essa força seria de fato o modo mais peculiar de exercer a sua liberdade. A partir da afirmação de Cálicles frente a Sócrates, se torna simples estabelecer um paralelo de proximidade entre sua postura e a defendida por Nietzsche em várias de suas obras, ao tratar da sua compreensão acerca da noção de vontade. Nas palavras de Nietzsche

E, onde há sacrifícios, serviços e olhares, amorosos: também aí há vontade de ser senhor. Por caminhos sinuosos o mais fraco se insinua na fortaleza e no coração do mais poderoso- ali rouba poder. E este segredo a própria vida me contou. "Vê", disse, "eu sou aquilo que sempre tem de superar a si mesmo". (NIETZSCHE, 2011 p.110)

O que Nietzsche busca descrever pelas palavras do seu Zaratustra, é que a sua vontade de poder não busca sublimação e dominação para com outros indivíduos, pelo contrário, busca uma constante superação de si mesmo, o jogo das potências que suprimem umas às outras, não se faz como espelho no corpo social, a vontade exclusivamente busca superar a si, fazendo no homem uma eterna construção. Diferindo de Platão, no seio de organização da ideia acrática, que seria a sua República. Todavia, pensemos a acrasia, como um conceito antropológico que reflete no político e não o inverso.

Outro diálogo platônico que merece atenção é o Protágoras, que discorre acerca da possibilidade de "ser vencido pelo prazer", nos moldes de um diálogo que gira principalmente entre o sofista e Sócrates, que na ocasião, não aceita a possibilidade da acrasia, propondo o hedonismo

\footnotetext{
${ }^{8}$ Tomamos a liberdade de utilizar esse termo para designar em Platão, em alguns de seus diálogos, o que consideramos uma postura próxima da vontade que seria exposta e desenvolvida posteriormente por Nietzsche. Não possuímos por intenção a afirmação forçosa e/ou anacrônica que exista na fillosofia platônica a noção de vontade nos moldes modernos. Tal termo foi colocado com fundo didático, visando melhorar a compreensão da proposta.

${ }^{9}$ (...) a verdade é que, nas almas dominadas pelas paixões e pelos apetites, o conhecimento não é efetivamente confiável. A multidão tem razão ao pensar que uma pessoa pode ter conhecimento (episteme), inteligência (phronesis) e reconhecer (gignoskei) o bem e o mal e ainda assim falhar em realizar o que recomenda o
} 
como consequência de uma hipotética postura acrática, opositor necessário e portanto danoso a sua teoria das virtudes racionais. Sócrates, ao contrário de seu discípulo, é incapaz de aceitar as inclinações e deslizes voltados ao prazer, que apresentamos enquanto constituintes inerentes a condição de ser humano.

Como tais potências não estão dissociadas ou distantes umas das outras, elas se apresentam como componentes do que temos como valores, mas não de modo absoluto, ou universal, pois esses valores tem de ser pensados como fluídos e flutuantes, num eterno jogo de forças, assim como descrito por Nietzsche: "E quem tem que ser um criador no bem e no mal, tem de ser primeiramente um destruidor e despedaçador de valores." (NIETZSCHE, 2011 p.111). Assim como Platão o faz para fundamentar a organização social da República, indo de encontro a estruturas básicas da Grécia antiga, apenas com uma linguagem menos incisiva.

Essa mesma vontade de potência é, portanto, força de destruição e de criação, assim como o próprio ciclo da vida; à medida que algo se esfacela, outro algo se constrói. Essa é a perspectiva nietzschiana de como as vontades se estabelecem, num embate constante. Essas oposições são constituintes necessárias da própria vida. Tal postura se reflete no próprio exercício dialético de Sócrates e seus interlocutores, a qual Nietzsche buscou partilhar, sempre remetendo a filosofia socrático-platônica, acreditando estar se distanciando ao manter esse embate agonal de ideias.

A proposta anterior sintetiza o que buscamos demonstrar. Encontrar na relação Nietzsche e Platão, apenas um movimento unilateral de crítica, seria uma simplificação danosa da sua filosofia, tivemos por intuito expor que mesmo o movimento de desconstrução de Nietzsche em relação ao platonismo, pode ser entendido como um movimento de exaltação.

A questão transmuta-se e se apresenta de forma mais completa e densa, devendo se pensar em como se deu a relação Nietzsche e Sócrates de modo a se configurar em alternâncias de opiniões que, segundo o próprio autor, era um modo particular de ser humano. Isso se considerarmos também que o ódio e a admiração são extremos que confusamente costumam estar bem próximos. Como descreve Fonseca

\footnotetext{
Nietzsche elogia Sócrates naquilo em que ambos são parecidos: o que é um problema para Sócrates também é um problema para Nietzsche como, por exemplo, a questão da moralidade. Porém, Nietzsche critica Sócrates pelo modo como Sócrates avalia os valores. Outra diferença fundamental está no modo como ambos valorizam a vida. A vontade de potência de Sócrates, o impulso fundamental de suas ações, é criticada, pois a vontade de potência socrática nega a vida e Sócrates não cria valores apenas para si, ao contrário, ele pretende que seus valores sejam válidos para todos. Expresso de outro modo, Nietzsche e Sócrates criam novos valores, mas, segundo Nietzsche, eles estão em polos opostos porque Sócrates é um decadente. (FONSECA, 2012, p.46)
}

conhecimento, escolhendo outra coisa por ter sido vencido. Em muitas pessoas o conhecimento falha em comandar a alma; nessas pessoas o conhecimento é ‘arrastado de um lado para o outro como um escravo' (352c1). (WEISS, 2006, p. 63, tradução nossa).

Cadernos Cajuína, V. 6, N. 1, 2021, p. 48-59. 
É possível então verificar o que talvez seria o motivo do profundo interesse de Nietzsche pelas questões provenientes do socratismo, ambos se apresentaram de modo a expor filosofias distintas, porém estas são, em certa medida, semelhantes, posto que a filosofia de ambos, buscou trabalhar com antagonismos, Nietzsche discutindo com a tradição e Sócrates e Platão com seus interlocutores.

A referida postura encontrada em Cálicles, Protágoras e Nietzsche, de uma nova forma de valorar e viver a vida em sua plenitude, pautada principalmente na execução de suas vontades. Tal postura poderia facilmente ser confundida com um hedonismo ${ }^{10}$ desenfreado da vida, todavia, esse não é o ponto principal a ser debatido, uma vez que devemos entender as posturas aqui expostas, não como dualismos ou antípodas imbricadas no filosofar platônico, com auxílio dos recursos retóricos socráticos, mas em sua raiz nevrálgica, a saber, a proposta existente em Nietzsche de reformular o platonismo, aparentemente expandindo noções de seus opositores. Nas palavras de Giacóia

\begin{abstract}
Eis, pois, onde poderíamos situar os fundamentos da oposição de Nietzsche a Platão e de seu projeto de inverter o platonismo. Inverter seria, então, simplesmente reverter, revalorizar o extremo oposto daquele valorizado pelo Sócrates platônico. Penso ser aqui fundamental distinguir o Nietzsche de fachada de um Nietzsche mais sutil, de intenções filosóficas abissais. Inverter o platonismo não significa, no fundo, retornar à sofística ou ao realismo cru de Tucídides; significa, antes, levá-lo além e acima de si mesmo, superá-lo e transfigurá-lo numa espécie de grandeza, profundidade e elevação cuja virtude não consiste na violência ou na crueldade da dominação física ou política, mas naquilo que se poderia denominar domínio de si, tornar-se senhor de seus próprios demônios. (GIACÓIA, 1997, p.33)
\end{abstract}

Todo o caminho conceitual percorrido por Nietzsche em relação a doutrina socráticoplatônica, possui como culminância a sua proposta de inversão do platonismo e de afirmação da vida como vontade de poder. Porém, não com o intuito de resgate total do que era anterior a essa doutrina, mas uma nova forma de trato consigo mesmo, com a liberdade, com o corpo e com a vida, e por quê não em consonância com a noção de acrasia platônica? Uma vez que o homem acrático exerce sua liberdade.

\title{
3. Conclusão
}

Ao longo da produção dessa pesquisa, buscamos ressaltar as proximidades dos pensamentos de Sócrates-Platão e Nietzsche, no que tange a constituição específica do termo acrasia em relação com vontade de poder, buscou-se demonstrar que por mais que em um primeiro olhar,

\footnotetext{
${ }^{10}$ Para Weiss, é inconcebível que Sócrates subscreva a rejeição da akrasia. Segundo a autora, o que o filósofo faz é distorcer e empobrecer deliberadamente sua descrição da personalidade humana, transformando as pessoas em simples perseguidores racionais de prazer, com o objetivo de refutar a alegação feita por Protágoras a respeito de sua capacidade para ensinar a virtude. Tal distorção, nos diz Weiss, acaba por produzir uma versão do paradoxo socrático que é não-socrática (NASCIMENTO apud WEISS, 2006, P. 67).
} 
ambos pareçam inconciliáveis, com um exame mais atento, podemos encontrar pontos em comum entre as duas perspectivas.

A partir da fundamentação do homem acrático para Platão, como um indivíduo que sucumbe as paixões em detrimento de uma postura racional mais centrada, buscamos estabelecer um paralelo com a filosofia nietzschiana que valoriza o que Platão despreza e despreza o que Platão valoriza, a saber, a primazia da razão, fruto da influência do intelectualismo socrático.

Partindo dessas concepções, buscando demonstrar nas entrelinhas do pensamento de Nietzsche, um de seus projetos mais ambiciosos, a proposta de inversão do sistema filosófico platônico, como buscamos expor, a concepção de muitos de seus termos e propostas, como opositores necessários das propostas de Platão, se mostram como essa tentativa de transvaloração, portanto, não parece absurdo ou implausível postular que o mesmo tenha acontecido na relação com a acrasia. Doravante, na esteira do pensamento nietzschiano, propomos uma relação entre ambos os indivíduos, o homem acrático platônico e o transvalorador nietzschiano, nos moldes de sua vontade.

Optamos por nos concentrar apenas em questões panorâmicas e pontuais, existindo muitas outras, com uma raiz mais profunda e tão significativa quanto, e que merecem ser investigadas em decorrência da vasta influência da filosofia platônica em Nietzsche, contudo, por uma questão de extensão, seriam inapropriadas de serem expostas nessa pesquisa.

Como mencionado anteriormente, esta é apenas uma possível aproximação que se mostra aparentemente pertinente, após argumentarmos em um primeiro momento acerca da constituição do homem acrático para Platão e em seguida acerca da vontade para Nietzsche, com o intuito de corroborar esse ponto, propomos uma proximidade da postura nietzschiana que visou uma relação de continuidade com opositores de Sócrates. Buscando não perder o fio interpretativo da questão proposta.

Nos amparamos em alguns interlocutores de Sócrates, que parecem superar seus argumentos em dados momentos dos diálogos Protágoras e Górgias, especulamos que a presença de tais figuras na obra platônica, refletem um vasto pluralismo conceitual, indo de encontro a rigidez de perspectivas comumente associadas a figura platônica. Esse poderia ser um movimento de transição, em relação com o desligar-se da influência de seu mestre.

Seguindo a linha de raciocínio contida no princípio dessa pesquisa, a interpretação apresentada é apenas uma entre as diversas possíveis para essa questão. Não tivemos por intuito conceitual a substituição ou superação de paradigmas interpretativos vigentes, mas de corroborar com as produções acadêmicas que são conduzidas acerca da relação conturbada, mas não distante, entre as filosofias de Platão e Friedrich Nietzsche. 


\section{Referências}

BARRENECHEA, Miguel. Nietzsche e o corpo. $2^{\text {a }}$ ed. Rio de Janeiro: 7 Letras, 2017.

BOBONICH, Christopher. Plato's Utopia Recast. New York: Clarendon Press - Oxford, 2002.

FEITOSA, Z. M. L. A questão da acrasia na filosofia de Platão. In: Prometeus Filosofia. v. 23, p.216-228, 2017.

FERRARI, G. R. F. The three-part soul. In: Plato's Republic, edited by G. R. F. Ferrari, New York: Cambridge University Press, 2007.

FONSECA, Ana Caroline. Os dois sentidos da crítica nietzschiana: Sócrates como um caso exemplar. In: Veritas, Porto Alegre, v. 57, n. 1, p. 41-51, jan. 2012.

GIACOIA, Oswaldo. O Platão de Nietzsche O Nietzsche de Platão. In: Cadernos Nietzsche, v. 3, p. 23-36, 1997.

NASCIMENTO, D. S. O problema da acrasia em Platão e Aristóteles. Tese (Doutorado em Filosofia) - Pontifícia Universidade Católica do Rio de Janeiro, 2013.

NIETZSCHE, F. Assim falava Zaratustra. São Paulo: Companhia das Letras, 2011.

Além do bem e do mal. São Paulo: Companhia das Letras, 1998.

PLATÃO, Protágoras, Col. Diálogos, tradução: Carlos Alberto Nunes, Belém: Ed. UFPA, 1980. A república, Col. Diálogos, tradução: Carlos Alberto Nunes, Belém: Ed. UFPA, 2000.

REIS, Dulce. Por uma nova interpretação das doutrinas escritas: A filosofia de Platão é triádica. In Kriterion, Belo Horizonte, n¹16, Dez/2017, p.379-398.

ROBINSON, Thomas. As características definidoras do dualismo alma-corpo nos escritos de Platão. Letras Clássicas, Universidade de Toronto, nº2, 1998, p.335-356.

WEISS, Roslyn. The socratic paradox and it's enemies. Chicago: University of Chicago Press, 2006. 